\title{
Enabling Technology Development Recommendations for the Next Decade and Beyond
}

September 15, 2020

\section{Submitted to:}

National Academy of Sciences

Planetary Science Decadal Survey 2023-2032

Topic: Technology Development

\section{Submitted by:}

\section{Dr. Brett Streetman}

The Charles Stark Draper Laboratory, Inc.

Release Notice

Copyright (C) 2020, The Charles Stark Draper Laboratory, Inc. Approved for public release
Technical Point of Contact

Dr. Brett Streetman

Phone:

email:

bstreetman@draper.com 


\section{ENABLING TECHNOLOGY DEVELOPMENT RECOMMENDATIONS FOR THE NEXT DECADE AND BEYOND}

\section{Introduction}

As part of a 2014 NASA Innovative Advanced Concepts (NIAC) Phase 1 grant, we completed a survey of the 2013-2022 Planetary Science Decadal Survey "Vision and Voyages" [1] with an eye towards technology development that could help leap ahead of the state of the art in planetary science missions. Filling the identified technology gaps would enable new classes of missions and enhanced scientific return. While the gap analysis is more fully described in the NIAC final report [2] and ensuing conference paper [3], a summary of the identified technology development needs, including passive landers of three varieties, guided atmospheric probes, robust sensing packages, and smaller remote sensing instruments, is presented here as input to the 2023-2032 Planetary Science Decadal Survey. A number of mission architecture ideas are discussed, but they are presented solely as examples to highlight technology enhancements, not as proposed or endorsed missions.

\section{2013-2022 Decadal Survey Analysis}

In addition to prioritizing objectives and missions, the decadal survey gives a concise summary of lines of research for planetary science in the form of a large number of unanswered questions about our solar system. This set of questions provides rich data to examine what types of missions and analyses are required to advance planetary science in the near-term, mid-term, and far-term periods.

We studied these questions to determine what type of mission architecture would most easily provide answers based on the type, quantity, and variety of new science data required. Figure 1 includes a breakdown of fundamental questions in the decadal survey. The questions are covered by three distinct categories:

1. Remote observation only or in situ observation only questions: These are questions which we both know how to ask and how to answer. We know where to go and what to look for in order to obtain the data necessary. These questions are the "low hanging fruit," so to speak, which could be answered in 5-10 years, given resources and prioritization. This category represents 84 of 161 questions (52\%) asked within the decadal survey. One example is "How does the atmosphere of Venus respond to solarcycle variations?” This is a pure remote observation question that can be answered with a spacecraft similar to the MAVEN mission to Mars. An example of an in situ only 
question is "How do the compositions of presolar grains and organic molecules vary among different comets?” Again, we know what data we need, we just have to obtain it by visiting multiple comets. A challenge, no doubt, but one that the last decade of exploration to small bodies has shown technologically feasible.

2. Advanced technology needs questions: These are the "high-hanging fruit" questions, generally requiring coordinated in situ and remote observations. We know how to answer these but they push the boundaries of traditional mission architectures and have a 10-20 year horizon and, thus, represent technology development exercises that should be undertaken as part of the upcoming decade. This category represents $19 \%$ of the explicitly asked questions and drives the technology gaps discussed here. An example from the decadal survey is "What can the significant differences among ring systems teach us about the differing origins, histories, or current states of these giant planet systems?” We need both a planetary-scale view to see the overall ring structure and an in situ view to get to resolve the fine detail within the rings to answer such a question. A different type of mission architecture that can fully satisfy the question in a single mission rather than two missions is needed. A second example question from the decadal survey is "What is the four-dimensional wind structure of the Martian atmosphere from the surface boundary layer to the upper atmosphere?” This question, and several others that are

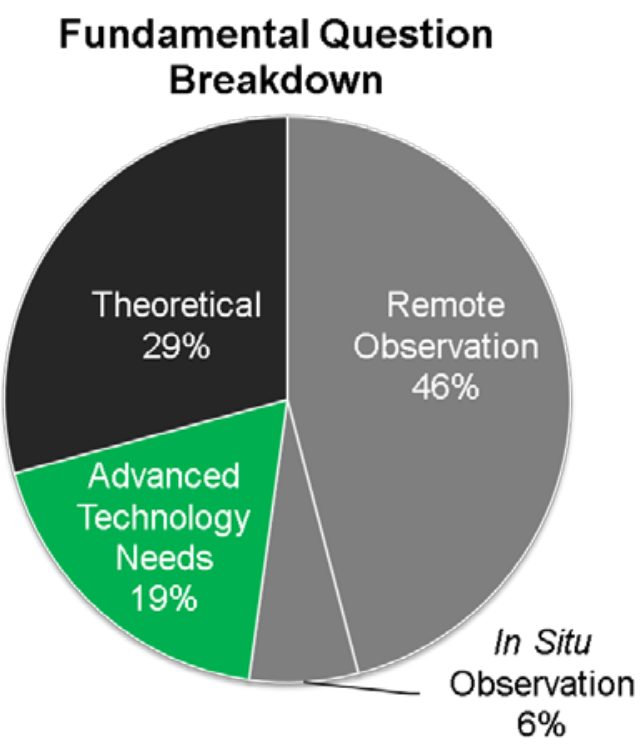

Figure 1. Breakdown of decadal survey question types meteorological in nature, requires global atmospheric data, coupled with a global network of in situ sensors.

3. Theoretical questions: This group of inquiries is looking for deeper answers. These are generally questions we do not know how to ask precisely enough to properly answer, and, thus, they have very long time horizons. Theory questions represent $29 \%$ of questions. An example of such a deep question is “Can evidence of life be found on Mars?” We have to agree on what evidence of life would look like before we can design a mission to find it.

A full categorization of the decadal survey questions and classifications is given in [2].

\section{Advanced Mission Classes and Technology Needs}

\subsection{Advanced Mission Classes and Examples}

Looking deeper at the identified advanced technology needs questions, we created notional 
mission scenarios to answer a number these questions with a single mission. Upon completing this exercise, three broad classes of mission architecture are evident:

1. Global Survey Chooses Local Site: The first mission class involves choosing the right landing or sampling location after mapping a quantity of interest remotely. This class is appropriate when there is a suspected spot of particular interest on a planet or body, but we can't know exactly where it is until we arrive. An example is the case study more thoroughly examined in [2], Example Mission 1 in Table 1: Gravimetry of an icy body to determine the locations of thinnest ice or most likely spot to gain access to subsurface material, followed by landing small in-situ sampling probes at the most promising location. This mission allows us to determine both the ice thickness and subsurface ocean composition with the same mission, something that would likely take decades otherwise. Another second example is Example Mission 2, which explores Saturn's (or other body's) rings from both a global and local perspective to achieve understanding of their structure at all scales. Such a mission would include both survey-class instruments and small probes that actually enter the ring system.

2. Dynamic/Reactive Science: The second class of architectures involves capturing transitory events on other bodies. Certain events are ephemeral, with hard-to-predict start and end times. A mission that can operate with the flexibility to wait for these events to occur is necessary. An example of this type of mission is Example Mission 3: a reactive orbiter that waits for active volcanoes and then releases probes to fly through the plume. We know these events are occurring at a body, but we cannot predict ahead of time where and when we need to be to capture them. Thus, we need an orbital platform that watches and waits for the transitory event and then releases a separate probe to capture it. A second example of this class, Example Mission 4, is a global weather satellite that monitors for new storms on a giant planet and then sends a probe into the eye of the storm.

3. Global In Situ Networks: The third class of missions involves deploying and communicating with global sensor networks. Many measurements of interest require a global network of in-situ samples. Generally a global asset is required to both deploy and communicate with the distributed network. Our first example of this class, Example Mission 5, is a seismic network at a small body. A global "mothership” deploys a network of seismic sensors to map internal composition of a small body. A second example of this class, Example Mission 6, is a global Martian LIDAR wind measurement network with reserved nodes deployed into active large scale dust storms detected from orbit.

Table 1 presents these six example missions and gives further description of the questions asked in the decadal survey to inspire each mission and then breaks down their technology development needs. Figure 2 shows a breakdown of the mission classes, their examples, and the technology development needs for each example mission. Again, these simple missions are thought exercises intended to explore the technology needs rather than serve as proposed or 
endorsed missions.

Table 1. Example missions to answer challenging questions posed in the decadal survey.

\begin{tabular}{|c|c|c|c|}
\hline $\begin{array}{l}\text { Example } \\
\text { Mission }\end{array}$ & Mission Idea(s) & Decadal Survey Question & $\begin{array}{l}\text { Technology } \\
\text { Development Needs }\end{array}$ \\
\hline 1 & $\begin{array}{l}\text { Gravimetry of an icy body to } \\
\text { determine the locations of } \\
\text { thinnest ice or most likely spot to } \\
\text { gain access to subsurface material } \\
\text { followed by landing small in-situ } \\
\text { sampling probes at the most } \\
\text { promising location }\end{array}$ & $\begin{array}{l}\text { Are volatiles present at the } \\
\text { surface or in the ice shell of } \\
\text { Europa that are indicative of } \\
\text { internal processing or } \\
\text { resurfacing? And many other } \\
\text { Europa questions }\end{array}$ & $\begin{array}{l}\text { Small scale gravimeter, } \\
\text { Passive landers } \\
\text { (impactors) }\end{array}$ \\
\hline 2 & $\begin{array}{l}\text { Explore Saturn's (or other body's) } \\
\text { ring from both a global and local } \\
\text { perspective to achieve } \\
\text { understanding of their structure at } \\
\text { all scales. Include small probes } \\
\text { that actually enter the ring system }\end{array}$ & $\begin{array}{l}\text { What is the mechanical process of } \\
\text { accretion up to and through the } \\
\text { formation of meter-size bodies? } \\
\text { Plus other ring related questions }\end{array}$ & $\begin{array}{l}\text { Small, cheap, disposable } \\
\text { camera/sensing package }\end{array}$ \\
\hline 3 & $\begin{array}{l}\text { Reactive orbiter that waits for } \\
\text { active volcanoes and then releases } \\
\text { probes to fly through the plume }\end{array}$ & $\begin{array}{l}\text { What are the inventories and } \\
\text { distributions of volatile elements } \\
\text { and compounds (species } \\
\text { abundances and isotopic } \\
\text { compositions) in the mantles and } \\
\text { crusts of the inner planets? Plus } \\
\text { other volcanism questions }\end{array}$ & $\begin{array}{l}\text { Guided atmospheric } \\
\text { probes, remote eruption } \\
\text { sensor }\end{array}$ \\
\hline 4 & $\begin{array}{l}\text { Global 'weather' satellite that } \\
\text { monitors for new storms on a } \\
\text { giant planet and then sends a } \\
\text { probe into a the eye of the storm }\end{array}$ & $\begin{array}{l}\text { What are the natures of periodic } \\
\text { outbursts such as the global } \\
\text { upheaval on Jupiter and the } \\
\text { infrequent great white spots on } \\
\text { Saturn? }\end{array}$ & $\begin{array}{l}\text { Guided atmospheric } \\
\text { probes, storm sensor }\end{array}$ \\
\hline 5 & $\begin{array}{l}\text { Seismic networks at small bodies. } \\
\text { A global 'mothership' deploys a } \\
\text { network of seismic sensors to map } \\
\text { internal composition }\end{array}$ & $\begin{array}{l}\text { What are the internal structures of } \\
\text { Trojans and KBOs? }\end{array}$ & $\begin{array}{l}\text { Passive landers (small } \\
\text { body), Seismic sensor }\end{array}$ \\
\hline 6 & $\begin{array}{l}\text { Global Martian LIDAR wind } \\
\text { measurement networks with } \\
\text { reserved nodes deployed into } \\
\text { active large scale dust storms } \\
\text { detected from orbit }\end{array}$ & $\begin{array}{l}\text { What are the processes } \\
\text { controlling the variability of the } \\
\text { present-day climate? What is the } \\
\text { four-dimensional wind structure } \\
\text { of the Martian atmosphere from } \\
\text { the surface boundary layer to the } \\
\text { upper atmosphere? What are the } \\
\text { primary causes behind the } \\
\text { occurrence of global dust events? } \\
\text { What are the processes coupling } \\
\text { the CO2, dust and water cycles? }\end{array}$ & $\begin{array}{l}\text { Weather sensors, Passive } \\
\text { landers (atmospheric) }\end{array}$ \\
\hline
\end{tabular}




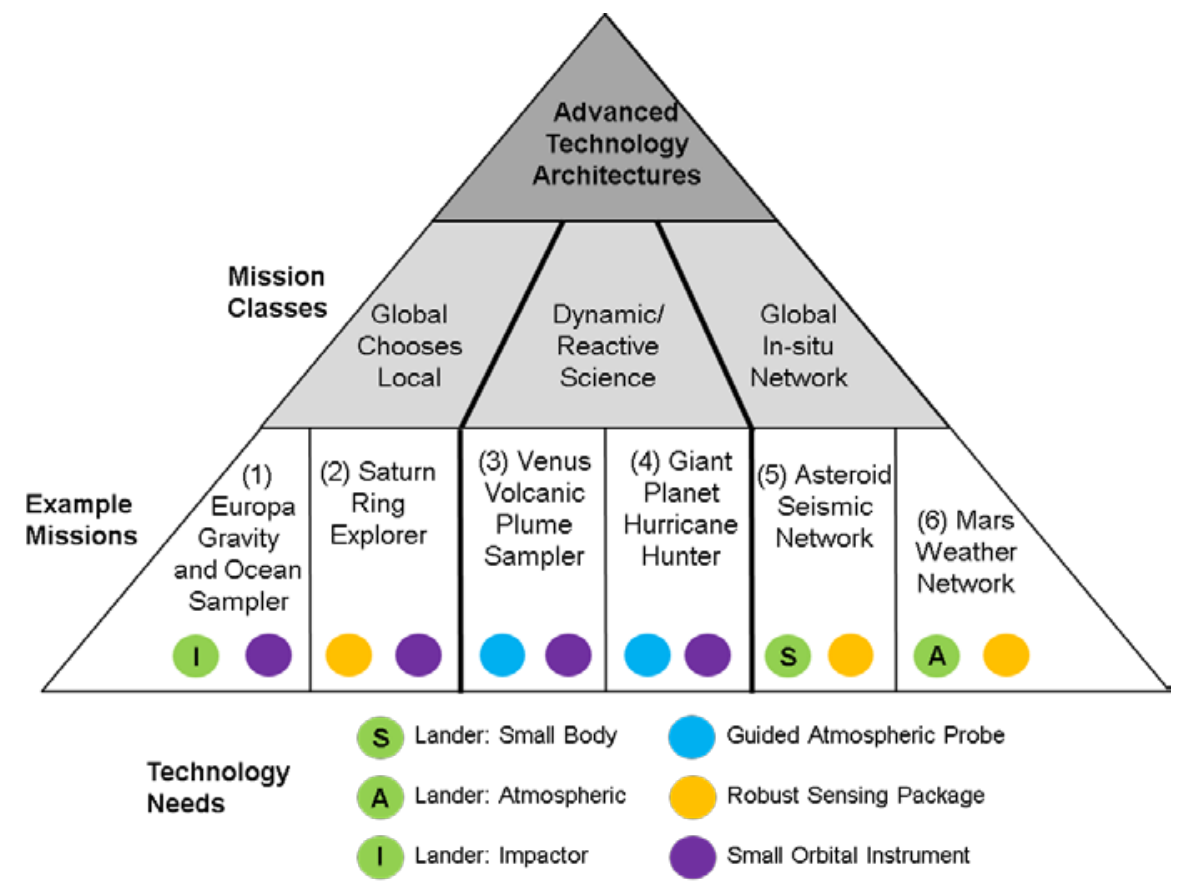

Figure 2. Mission classes, examples, and technology needs

\section{Technology Needs for Identified Mission Architectures}

From the three mission classes and their examples listed in Table 1, four major technology categories appear that need more development to make such missions possible. These "tools" appear throughout mission ideas that seek to answer these challenging, longer time-horizon questions in planetary science. The categories are:

1. Passive Landers: Needed for getting from orbit to the in situ environment with minimal mass requirements. Traditional propulsive landers are generally size and cost prohibitive for smaller classes of missions (except perhaps to the Moon). Passive (i.e. nonpropulsive) landing technologies must be robust enough to ensure mission success. However, an important distinction between traditional mission architectures and many of the example missions is robustness through numbers: single in situ sensors are unimportant as long as enough survive to complete the mission. Three distinct versions of landers are needed:

a. Small body, for asteroids/comets. These impact with very low speeds, but must remain on the body (i.e. not bounce off). The inelastic collision of the lander on the body can be the most challenging aspect of design, as demonstrated by the Rosetta mission. Successes of recent missions such as Hyabusa2, show that significant progress has already been made on such landers [4].

b. Atmospheric, for large bodies with significant atmospheres. The presence of atmosphere can help with passive landing, especially for very small probes. At the extreme, some designs with very low area-to-mass ratios can survive with no heat protection at all [5]. 
c. Impactors, for moons and other significant bodies without atmosphere. As bodies grow larger without an atmosphere, passive landers must survive larger and larger impact velocities, introducing in new design challenges. A sufficient number of impactor landers must survive the impact such that the mission still succeeds. Such an analysis for Europa is given in [2].

2. Guided Atmospheric Probes: Needed for sampling specific places in an atmosphere or landing on specific surface locations. Passive landers are designed to land where they may, but many missions require passage through or landing on a specific location. These missions tend to occur on atmospheric bodies, with the goal of sampling phenomena like volcanic plumes, storm regions, or areas with a higher concentration of a gas species of interest. Such probes have been proposed for a number of mission concepts, e.g. [6] for Venus, but have not been developed.

3. Robust Sensing Packages: Needed for reliably operating away from a mothership in highly challenging environments (e.g. rings, high radiation zones). These sensing units are considered to be somewhat disposable, or perhaps even planned for destruction. They go to locations that are inaccessible to a main spacecraft asset and must reliably capture and return data before succumbing to the environment. In operating away from the main orbital asset, the overall mission is protected. Remote-operating packages have been executed for small body missions such as [4] and proposed for numerous missions for diverse applications such a flying swarms on Mars [7], and chip-scale, free-flying sensors [2].

4. Small, Precise Orbital Instruments: The ideal advanced mission provides the benefits of both the remote observation and in situ modes of exploration in the same scale package. In addition to the in-situ technologies listed above, these mission classes require the continued miniaturization and improvement of remote sensing units. The proliferation of CubeSat and similar spacecraft over the last decade has driven the development of many miniaturized sensors [8], but instruments specific to planetaryscience needs should continue to be advanced.

Development in the above technology categories will help drive towards innovative missions inthe next decade and beyond, allowing for advanced science data collection with smaller and cheaper missions. Many technology developments will be pursued in the next decade of planetary science mission development, but our analysis of the current decadal survey reveals a need for these four classes of technologies that will enable efficient data collection for the challenging far-term questions posed by the planetary science community. Thus, we propose the following recommendation:

Forward-looking technology development plans should include Passive Landers, Guided Atmospheric Probes, Robust Sensing Packages, and Small, Precise Orbital Instruments. These four classes of technologies open many new mission architectures to help answer some of the more challenging questions in planetary science, especially beyond the next decade. 


\section{References}

[1] National Research Council, "Visions and Voyages for Planetary Science in the Decade 2013-2022," National Academies Press, 2011.

[2] B. Streetman, J. Shoer, R. Stoner, M. A. Peck, Z. Manchester and L. Weiss, "Exploration Architecture with Quantum Inertial Gravimetry and In-Situ ChipSat Sensors.[NIAC Phase I Final Report]," NASA, 2015.

[3] B. Streetman, J. Shoer, R. Stoner and M. A. Peck, "Dual exploration architectures for breaking the decades-long cycles of planetary science," in 2016 IEEE Aeropsace Conference, Big Sky, MT, 2016.

[4] T. Ho, V. Baturkin, C. Grimm and .. etal, "MASCOT-The Mobile Asteroid Surface Scout Onboard the Hayabusa2 Mission," Space Sci Rev, vol. 208, pp. 339-374, 2017.

[5] J. Atchison, Z. Manchester and M. A. Peck, "Microscale Atmoshperic Re-Entry Sensors," in International Planetary Probe Workshop 2010 (IPPW-7), Barcelona, Spain, 2010.

[6] J. Balcerski, G. Hunter, D. Makel, S. Colozza and M. Zborowski, "LEAVES: Lofted Environmental and Atmospheric Venus Sensors," NASA, 2019.

[7] J. Bluman, C. Kang, D. Landrum, F. Fahimi and B. Mesmer, "Marsbee- Can a Bee Fly on Mars?," in 55th AIAA Aerospace Sciences Meeting, 2017.

[8] J. Kopacz, R. Herschitz and J. Roney, "Small satellites an overview and assessment," Acta Astronautica, vol. 170, pp. 93-105, 2020.

\section{Acknowledgement}

The content for this paper was generated under NASA Contract No. NNX14AM90G.

Use or disclosure of data contained on this sheet is subject to the restrictions on the title page of this White Paper 